\author{
Cadernos de \\ ESTUdOS LINgüĺsticOS - (56.2), Campinas, Jul./Dez. 2014
}

\title{
DISCUTINDO ANÁLISE DE CONTEÚDO COMO MÉTODO: O \#DIADACONSCIÊNCIANEGRA NO TWITTER
}

\author{
RAQUEL RECUERO \\ Universidade Católica de Pelotas
}

\begin{abstract}
RESUMO: O trabalho busca explorar o discurso sobre o Dia da Consciência Negra no Brasil, através do Twitter. Há dois objetivos: (1) Explorar as contribuições de um design metodológico de Análise de Conteúdo com foco referencial e Análise de Redes para grandes conjuntos de dados, especialmente aqueles coletados em sites de rede social e; (2) Discutir como as redes de conceitos auxiliam a compreender, através da exclusão e da presença, o discurso sobre a data. Para tanto, foram coletados e analisados mais de 2 mil tweets. Os resultados apontam para um discurso de exclusão do negro enquanto ator, uma marginalização deste e redução de seu sentido àquele da descrição da data.

Palavras-chaves: Análise de Conteúdo. Twitter. Redes Sociais.
\end{abstract}

ABSTRACT: This paper explores the discourse about the Black Awareness Day in Brazil, through Twitter. Two objectives are key for this discussion: (1) To explore contributions from Referential Content Analysis and Network Analysis to unveil discourses in large datasets such as the ones collected in social network sites and; (2) To discuss how the networks of concepts allow through exclusion and presence, the inferences about the discourse. In order to do this, we collected and analyzed more than two thousand tweets. Results point to the exclusion of "black" as an actor in the debate, the marginalization and interdiction of the cause and the reduction of the "black" to the description of the date.

Key-words: Content Analysis. Twitter. Social Network Sites.

\section{INTRODUÇÃO}

Pouco ainda se estuda, hoje, a respeito dos discursos que são legitimados e reproduzidos nos sites de rede social e seus impactos na sociedade, de modo particular, no Brasil. E isso embora tenhamos, hoje, mais de 55\% da população brasileira com acesso à Internet ${ }^{1}$, dos quais, mais de 76 milhões de usuários ativos apenas no Facebook ${ }^{2}$ e mais de 30 milhões no Twitter ${ }^{3}$, e cada vez mais dados disponíveis (só o Twitter estima, por exemplo, a publicação de mais de 58 milhões

\footnotetext{
${ }^{1}$ Dados do Comitê Gestor da Internet Brasileira e do CETIC referentes a 2012 - http://www. cetic.br/usuarios/tic/2012/C2.html

2 http:/www1.folha.uol.com.br/tec/2013/08/1326267-brasil-chega-a-76-milhoes-de-usuarios-nofacebook-mais-da-metade-acessa-do-celular.shtml

${ }^{3} \mathrm{http}: / /$ www.bbc.co.uk/portuguese/noticias/2013/03/130322_twitter_contas_inativas_rw.shtml

${ }^{4} \mathrm{http}$ ://www.independent.co.uk/voices/comment/what-we-can-learn-from-the-numbers-twitterand-facebook-dont-want-us-to-see-9029152.html
} 
de novos tweets por $\mathrm{dia}^{4}$ ). Assim, embora milhares de tweets, posts no Facebook, mensagens etc. sejam publicados todos os dias e circulem pelas mais variadas esferas sociais, pouco se faz no sentido de compreender seus efeitos e impactos, suas condições de produção e, mesmo, às formações discursivas que se filiam. Isso se deve à complexidade dos designs metodológicos necessários para tais estudos, especialmente no que diz respeito à coleta e análise dos dados em larga escala.

Neste sentido, a Análise de Conteúdo (AC) tem sido cada vez mais utilizada por diversas áreas para compreender e debater os discursos que são espalhados pelo ciberespaço. A junção dos elementos dos públicos mediados (Boyd, 2010) e notadamente, a permanência das interações e sua "buscabilidade", bem como a disponibilidade dos dados das "falas" de milhares de atores nos sites de rede social (Boyd \& Ellison, 2007) têm dado o tom para o crescimento dessas abordagens.

Dentro desta perspectiva, de caráter um pouco mais experimental, buscamos, neste artigo, observar de que modo novos designs metodológicos podem ser constituídos para os estudos da linguagem no ciberespaço. Optamos, assim, por desenhar um estudo focando o Twitter, e circunscrevê-lo a um contexto específico, o Dia da Consciência Negra. Nossa proposta intersecciona duas abordagens metodológicas distintas: a Análise de Conteúdo (AC) e a Análise de Redes (Clustering Analysis), notadamente através dos conceitos da Análise de Redes Sociais (ARS) (Wasseman e Faust, 1994) e de Análise de Relações (Bardin, 2007). O objetivo é compreender quais sentidos podem ser reconstruídos através da extração de coocorrências de palavras em um conjunto de dados de tweets sobre o mesmo assunto, utilizando unicamente tweets em Português do Brasil, e quais formações discursivas podem ser inferidas pelas correlações entre os conceitos observados.

\section{REDES SOCIAIS NA INTERNET, DISCURSO E VIOLÊNCIA}

Antes de iniciar a discussão sobre a abordagem da Análise de Conteúdo, é preciso discutir como os sites de rede social e as redes sociais na internet vão construir novos espaços discursivos e como esses espaços podem desvelar formas de compreender a circulação e a legitimação dos discursos.

\subsection{Redes Sociais na Internet}

A metáfora das redes sociais já foi utilizada por diversos autores muito antes da Internet. Em Sociologia, por exemplo, toda uma área de estudos, inaugurada pelo trabalho de Jacob Moreno, buscou estudar as "redes sociais" (Scott, 2004). Trata-se de um enfoque de viés estruturalista, que busca entender os grupos sociais através de suas conexões, nos quais os atores sociais são os nós (ou nodos) da rede e suas conexões, os laços sociais. O objetivo é estudar os grupos através de sua estrutura e compreender quais propriedades advém dela. A metáfora dos grupos como redes deu origem também a um foco de estudos específico, denominado de "Análise de Redes Sociais". A perspectiva buscou modos de estudar as redes e medi-las, utilizando especialmente suas propriedades a partir da teoria dos grafos (Wasseman \& Faust, 1994; Scott, 2004; Degenne e Forsé, 1999). O estudo das redes sociais, portanto, não é novo. Por que falamos, então, em "redes sociais na internet"? 
As chamadas "redes sociais na internet" são representações de grupos sociais, constituídas com o apoio dos sites de rede social (Recuero, 2009). São estruturas estabelecidas através da apropriação desses sites que, por sua vez, constituem-se em ferramentas que permitem aos atores a construção de um perfil individual e a publicação de suas conexões sociais (Boyd \& Ellison, 2007). Dizemos que tais redes são metafóricas porque a estrutura das redes sociais, na verdade, compreende elementos de desgaste e interação constitutiva dos laços que não necessariamente estão presentes online. Assim, na internet, as redes sociais são transcritas não de forma análoga ao off-line, mas reinterpretadas e reconstruídas com características novas e com novas implicações. Essas implicações apontam para redes sociais mais amplas e mais complexas, com a emergência de novos valores simbólicos e novas formas de acesso a eles (Ellison, Steinfeld e Lampe, 2008), novos modos de conexão (Rosen, Steffanone e Lackaff, 2010) e a construção de novas audiências (Bernstein et al, 2013).

Por causa dessas mudanças, tais redes constituem-se em novos tipos de espaços públicos, os chamados públicos em rede (Boyd, 2010). Esses públicos têm características específicas. Boyd (2010) explica que esses públicos compreendem, ao mesmo tempo, o espaço construído pelas tecnologias e o coletivo que emerge do uso dessas tecnologias. Por isso, os públicos em rede têm dois tipos de características, as relacionadas a este espaço e as relacionadas suas apropriações ou dinâmicas. Dentre as características do espaço, estão: 1) a permanência dos textos, ou seja, o fato de que as interações (textos) tendem a ficar inscritas na rede e ali permanecerem; 2) a "buscabilidade" dos textos, que são recuperáveis; 3) a replicabilidade dos textos, que podem ser reproduzidos facilmente e de forma fiel, o que leva a ; 4) a escalabilidade, ou seja, o potencial de alcance e multiplicação desses textos. Já entre as características das dinâmicas desses públicos, contam-se: 1) a presença de audiências invisíveis, ou seja, o fato de que os participantes não estão completamente visíveis/discerníveis na rede; 2) o colapso dos contextos, marcado pela permeabilidade das fronteiras temporais da Rede; 3) o frequente "borramento" das fronteiras entre o público e o privado.

Essas características nos mostram que há uma mudança no suporte da interação, que vai permitir que as conversações, antes mapeadas unicamente pela observação, tornem-se mais facilmente registradas. É aí que vemos a importante demarcação: pela primeira vez, graças ao advento e à apropriação dos sites de rede social, os atores passam a registrar seus passos, suas conversas, suas interações e redes, dando origem aos mais diversos estudos sobre a linguagem e a "nova mídia" (Baron, 2011). Com isso, o mapeamento dessas redes ganha novo potencial, com ares de "big data", no sentido de que, pela primeira vez, é possível mapear gostos, atos, ideias e conexões de milhares de pessoas, procurar e estabelecer padrões entre essas múltiplas redes, principalmente através das interações que são mediadas por essas ferramentas. Assim, começam a tornar-se comuns estudos com métodos diferenciados e múltiplos, na tentativa de compreender essas redes e os modos como os discursos são reproduzidos, legitimados e excluídos nelas (cf. Page, 2012 e Zappavigna, 2011).

${ }^{5}$ Termo utilizado para referenciar grandes quantidades de dados que necessitam de apoio computacional para análise, dada a sua complexidade diante dos métodos tradicionais. Mais aqui: http://en.wikipedia.org/wiki/Big_data (Acesso em Janeiro de 2014) 
O Twitter, foco deste trabalho, já teve suas características defendidas como aquelas de site de rede social (Recuero e Zago, 2009). Ele é uma ferramenta que permite a seus usuários publicar pequenos textos, de 140 caracteres (no máximo), para outros usuários (os "seguidores), bem como receber os textos de outros (os "seguidos"). Por conta dessa possibilidade de constituir redes de audiência em rede e da possibilidade de construção de perfil individualizado, tem elementos de sites de rede social. Embora o foco inicial da ferramenta estivesse na publicação de mensagens sobre o cotidiano (Zago, 2008), as apropriações da ferramenta há muito já superaram essas características. Seu uso conversacional no viés síncrono, por exemplo, já foi estudado por diversos autores (Boyd, Golder e Lotan, 2010; Honeycutt e Herring, 2009 entre outros). Esse uso é particularmente interessante para este trabalho, uma vez que o Twitter, assim, passa a ser compreendido como um espaço discursivo na Contemporaneidade. De modo especial, sua apropriação pelos jovens e adolescentes ${ }^{6}$ no Brasil pode oferecer um espaço de compreensão de formações discursivas ${ }^{7}$ (Foucault, 2009) muito presentes na nossa sociedade, mas não necessariamente desveladas.

\subsection{Discurso, Violência Simbólica e os Sites de Rede Social}

Outros elementos relevantes para a discussão que este trabalho propõe estão nos discursos e na violência simbólica que acarreta exclusão. Inicialmente, explicito que o viés teórico que demarca esta proposta está também ancorado nos estudos de Foucault, e especialmente, na sua obra A Ordem do Discurso (1999). Para o autor, o discurso é uma forma de representação e reprodução ideológica, que compreende "o domínio geral de todas as afirmações, algumas vezes como um grupo individualizado de afirmações, outras vezes, como uma prática regulada que reflete um número de afirmações" (p.80). As coisas, os sujeitos e os objetos são constituídos pelo discurso, pelo dito que gera o saber (Giacomoni e Vargas, 2010). Os enunciados de um discurso, em suas regularidades, filiam-se a determinadas formações discursivas, que caracterizam e delimitam temáticas e o que é dito sobre elas (Foucault, 2009). Assim, discurso, poder e ideologia são indissociáveis na percepção de Foucault sobre as práticas que vão moldar o conhecimento. O poder, ainda, é exercido e desafiado pelo discurso. Entretanto, está também disfarçado nas práticas discursivas, de modo a manter a dominação através da legitimação da hegemonia. Observamos, portanto, que as falas que são constituídas nos sites de rede social e que ali permanecem e circulam também estão submetidas às relações de poder e ideologia que constituem os sujeitos desses discursos. E com isso, podem traduzir também elementos-chave para a compreensão dessas dominações.

\footnotetext{
${ }^{6}$ Nos últimos meses, mais e mais estudos têm sido divulgados de forma a mostrar a migração da presença dos adolescentes para o Twitter. Vide http://www1.folha.uol.com.br/tec/2013/12/1390659facebook-esta-morto-e-sepultado-diz-estudo.shtml e http://www.pewinternet.org/Media-Mentions/2013/ Poll-Teens-migrating-to-Twitter.aspx (Acesso em Janeiro de 2014).

${ }^{7}$ Utilizamos aqui a noção de Formação Discursiva como aquela do conjunto de enunciados que têm uma regularidade (em termos de escolhas temáticas, tipos de enunciação, conceitos e etc.) conforme discutida por Foucault (2009).
} 
De forma semelhante, Bourdieu (1991) também vê o discurso como uma forma de legitimação da dominação (em sentido econômico e simbólico). Ele privilegia as trocas linguísticas como "relações de poder simbólico", ou seja, momentos onde as relações de poder (e dominação) entre os falantes são atualizadas (p.37). Essas relações são impostas através do que ele chama de "violência simbólica", ou seja, a imposição de determinadas percepções sobre os dominados, os sujeitos, que são então naturalizadas. É a imposição do discurso dos dominantes sobre os dominados, que, assim, reconstrói e determina as estruturas da dominação, e legitima a ordem social vigente. O discurso, assim, tem função de manter a ordem dominante. Essa função é exercida, também, a partir dos sistemas de exclusão.

Foucault (1999), explica a existência e a ação dos sistemas de exclusão. A a produção do discurso é controlada. Esse controle é essencialmente importante, pois é através dele que alguns participam e alguns são excluídos, que alguns temas são aceitos e outros são proibidos. $\mathrm{O}$ autor propõe a hipótese segundo a qual:

(...) em toda a sociedade a produção do discurso é ao mesmo tempo controlada, selecionada, organizada e redistribuída por certo número de procedimentos que têm por função conjurar seus poderes e perigos, dominar seu acontecimento aleatório, esquivar sua pesada e temível materialidade (p.p. 8-9)

O discurso, assim, controla como e onde um determinado tópico pode ser discutido e apresentado (Hall, 2001) e é marcado por um sistema de exclusão, dentro de sua função regulatória. Esses sistemas de exclusão reforçam os sistemas de dominação. Há processos internos (do próprio discurso) e externos (da sociedade) de controle e exclusão do discurso, bem como processos de controle dos sujeitos (Foucault, 1999). Esses processos de exclusão, elencados de forma genérica, têm um papel fundamental em definir o que pode ser dito e por quem pode ser dito. Assim, o discurso é passível de uma dupla leitura: aquela do que está explícito e aquela do que não está. Essas leituras podem auxiliar a compreender aquilo que está excluído do discurso.

Dentre os processos de exclusão elencados por Foucault (1999), interessam-nos neste trabalho, primeiramente, os externos, que são três:

a) a interdição (ou a "palavra proibida") - para o autor, refere-se ao fato de que nem todos podem falar e nem tudo pode ser dito. A interdição, assim, refere-se tanto ao assunto quanto àquele que fala.

b) a segregação da loucura - refere-se à separação e a rejeição do sujeito que fala porque seu discurso não pode circular como os demais, "não tendo verdade e nem importância" (p. 8).

c) oposição do verdadeiro e falso (ou "vontade de verdade") - refere-se ao modo como o saber é aplicado e valorizado por uma sociedade. É apoiada pelas instituições e pela pressão do que é reconhecido como "verdadeiro" e assume, assim, "tarefa de justificar a interdição e definir a loucura" (p.30). 
Neste trabalho, focaremos principalmente sobre a questão da interdição, ou seja, do que não é dito, do que não pode ser dito. Foucault (1999) fala especificamente de três formas de interdição:

a) a palavra proibida ou tabu do objeto - refere-se a coisas e assuntos sobre os quais não se pode falar. São assuntos que são proibidos, são tabu.

b) ritual da circunstância - refere-se à circunstância em que certos discursos podem ser enunciados.

c) direito privilegiado ou exclusivo do sujeito que fala - apenas determinados sujeitos podem dizer certas coisas.

Essas formas de exclusão têm efeitos e constituem-se dentro de um sistema de dominação simbólica, onde os discursos legitimam e reforçam elementos de diferenciação de classe e raça, notadamente econômicos.

Mas como esses sistemas funcionam no espaço online? Os públicos em rede (Boyd, 2010) também demarcam um novo espaço discursivo, com características próprias que interferem nos modos através dos quais os discursos são construídos. Compreendendo a noção de "espaço discursivo" a partir de Foucault (1986), ela é construída como o espaço (material) onde o conhecimento e os sentidos são operacionalizados, a fronteira material do contexto do discurso. Embora as perspectivas desse espaço sejam alardeadas como positivas em termos da pluralidade e do acesso a discursos diferentes (Castells, 2003), autores como Herring (2001) argumentam que o discurso na internet "herda" as assimetrias das estruturas econômicas e sociais vigentes (p. 12). Essa característica de refletir parte dessas assimetrias é essencial, na medida em que pode auxiliar os pesquisadores a desvelar parte desses constructos que são expressos e legitimados também no espaço online.

Há vários estudos sobre essas assimetrias. Souza, Amaral e Guimarães (2011) discutem o uso do Twitter na reconstrução de discursos em torno de uma agressão contra um professor. Rambe (2012), também focando o Facebook, estudou relações de poder e autoridade nos discursos de professores e alunos, mostrando a prevalência da hierarquia. Walton e Jaffe (2011) também exploram essas assimetrias em blogs, enfatizando a reprodução de estereótipos raciais e de classe. Como vemos, o online parece expor de forma mais clara determinados discursos dominantes, possivelmente pela própria caracterização do espaço como aquele dos públicos em rede.

\subsection{Dia da Consciência Negra e o Discurso sobre o Negro}

Finalmente, outro ponto que necessita ser desenvolvido refere-se ao discurso "do" e "sobre" o Negro. Ora, o Dia da Consciência Negra circunscreve o contexto selecionado para este trabalho. Trata-se de uma data ${ }^{8}$ alusiva à reflexão e ao debate sobre inserção do negro na sociedade brasileira, particularmente devido

\footnotetext{
${ }^{8}$ Lei 12519 - http://www.planalto.gov.br/ccivil_03/_Ato2011-2014/2011/Lei/
} 
ao período de escravidão e à segregação social sofrida. Coincide, também, com a data da morte de Zumbi dos Palmares, considerado um símbolo da resistência à escravidão no Brasil durante o século XIX. A data é um feriado facultativo, ou seja, cada município decide se o observa ou não. Entretanto, o número de cidades que observa o feriado do Dia da Consciência Negra é pequeno, chegando a menos de $20 \%$ em $2013^{9}$.

Freitas (2012) detalha a dominação sofrida pela população negra no Brasil desde a escravidão. Para a autora, o negro no Brasil acumulou grande perda de direitos, que políticas públicas jamais conseguiram reverter. Bento e Berghin (2005) defendem que essas circunstâncias históricas constituíram um sistema de dominação, no qual o negro é excluído, em prol da manutenção do status quo de dominantes e dominados. Essa exclusão dá-se de muitas formas, como através da ausência na mídia (Golzio, 2004). Essa ausência, a exclusão, é também uma forma de violência simbólica.

Essas perspectivas apontam a questão racial como uma questão relevante, uma vez que parte das pesquisas sobre as potencialidades comunicativas da internet trazem a questão da "liberação do polo da emissão" (Lemos, 2008) como um indicativo de sua democratização e da pluralidade possível dos discursos que ali são expressos.

É, portanto, a partir deste viés que buscamos o tema e a análise deste trabalho. Passemos, pois, à discussão da abordagem metodológica utilizada.

\section{ABORDAGEM METODOLÓGICA}

Neste tópico, discutiremos brevemente a abordagem metodológica que utilizamos para abordar as questões de que este trabalho trata. Acima, explicamos que nosso objetivo discutir de que modo a construção de um design metodológico com base na Análise de Conteúdo e na Análise de Redes pode auxiliar no estudo dos discursos nos sites de rede social, notadamente, no Twitter. O caso em questão refere-se ao Dia da Consciência Negra e à identificação de conceitos e relações que tornem um pouco menos opaca a discussão sobre a data e os discursos que permeiam os grupos e que são estabelecidos no Twitter. Para isso, discutiremos a seguir a abordagem metodológica proposta.

\subsection{A Análise de Conteúdo}

A análise de conteúdo (AC) não é uma abordagem nova. Krippendorf (2012) explica que há três características que distinguem a abordagem "contemporânea" da AC de outras formas de estudo. A primeira delas é sua fundamentação empírica, que privilegia especialmente os textos, procurando compreender seu sentido para os atores sociais. A segunda é a transcendência das noções de símbolo, conteúdo

9 http://www.estadao.com.br/noticias/cidades, dia-da-consciencia-negra-menos-de-20-das-cidades-aderem-ao-feriado, 1098687,0.htm (Acesso em Janeiro de 2014.) 
e intenções. Krippendorf explica que é preciso enfatizar mensagens, canais, comunicações e sistemas. O terceiro elemento é o desenvolvimento metodológico, que teria características um pouco diferenciadas, como o foco em grandes conjuntos de dados e contextos mais amplos e complexos. A AC, assim, é uma técnica de pesquisa para construir "inferências" a partir de textos para seus contextos de uso (Krippendorf, 2012, p.24).

Bardin (2007) também salienta a produção de inferências como um dos elementos fundamentais da Análise de Conteúdo, salientando ainda a necessidade da "desocultação" como um dos principais desafios do método (p.7). A autora salienta ainda as práticas da AC como constituídas de descrição, inferências e interpretações.

Assim, os primeiros passos utilizados neste trabalho foram:

a) Amostra de Textos - Para este trabalho foram considerados como textos todos os tweets ${ }^{10}$ recolhidos na coleta de dados (Vide item 3.3). Para produzir um tweet é necessário ter uma conta no Twitter e estar utilizando o sistema. A publicação é realizada sob um nome de usuário ao qual fica conectada. Os tweets podem conter hashtags ${ }^{11}$; menções (citações a outros usuários utilizando-se o sinal “@”)" ${ }^{12}$; e retweets (replicação de uma mensagem de outro usuário, normalmente antecedida por um “RT").

Os tweets foram coletados de forma automática, utilizando-se de crawler específico para coletar tweets que continham determinadas palavras-chaves. No nosso caso, foram feitas seis coletas durante o dia 20 de novembro, sempre pela hashtag \#diadaconsciencianegra e pelas palavras "consciência negra". Para essas coletas, utilizamos no programa NodeXL ${ }^{13}$. As coletas foram realizadas entre as 10 e as 15 horas, uma por hora, quando o crawler obtinha o máximo de tweets que o Twitter permitia ser coletados de sua $\mathrm{API}^{14}$. No total, após as seis coletas, foram agrupados 2260 tweets únicos (mensagens publicados por atores diferentes) e 2328 atores citados. Esses tweets, assim, constituíram no corpus de análise deste trabalho.

b) Contextos - Os textos analisados só terão sentido dentro de um determinado contexto. Portanto, é essencial que se situe o material no contexto do Twitter e na data, conforme fizemos no capítulo anterior.

c) Construtos Analíticos - O construto analítico, para Krippendorf(2012), constitui-se no modo de operacionalização do texto em relação ao contexto. Neste trabalho, focaremos construtos simples. Nosso objetivo é compreender como os textos (ou "falas") no

\footnotetext{
${ }^{10}$ Um tweet é um texto de até 140 caracteres publicado no Twitter.

${ }^{11}$ Hashtags são "etiquetas" que são utilizadas para demarcar contexto e que são passíveis de recuperação. São identificadas pelo uso do sinal "\#”.

${ }^{12}$ Para mais detalhes a respeito das funções da “@” no Twitter, ver o texto de Honeycutt \& Herring (2009) sobre conversação no Twitter.

${ }^{13} \mathrm{http}: / /$ nodexl.codeplex.com/

${ }^{14}$ Application Programming Interface.
} 
Twitter podem indicar percepções e discursos a respeito do Dia da Consciência Negra no Brasil. Para tanto, utilizaremos os tweets e extrairemos deles os principais conceitos que guiam as falas dos atores (aqueles que, no corpus, aparecem com maior frequência). Os construtos, assim, serão analisados em contraposição a outros conceitos, a partir de suas co-ocorrências nas falas dos atores.

d) Análise de Relações - Bardin (2007, p.191) indica, dentre os tipos de análise de conteúdo, a chamada "análise das relações". Para a autora, a análise das co-ocorrências é a que "procura extrair dos textos as relações entre os elementos da mensagem" (p. 191) e assinalar os fragmentos e exclusões dos elementos em uma mesma unidade contextual. A autora explica que a análise de co-ocorrências pode apresentar elementos significativos ou ausências significativas. Dentre os autores que trabalharam com esse foco, destaca o trabalho de Osgood (1959), principalmente pelos passos procedimentais que ele seleciona.

O procedimento de Osgood (1959), seguido neste trabalho, é composto por:

1) escolha das unidades de registro - nesse processo, foram escolhidas as palavras que apareciam com maior frequência nos tweets. Palavras com sentidos aproximados para o locutor, de acordo com o procedimento, foram incluídas no mesmo grupo.

2) escolha das unidades de contexto e recorte - no caso, foram escolhidas as unidades referentes às palavras mais frequentes nos textos coletados, no recorte contextual explicitado anteriormente.

3) codificação e construção de matrizes - procedimentos que foram realizados com o auxílio do software Textometrica ${ }^{15}$.

4) Análise de Redes/Clusterização - que foi traduzida segundo proposta de análise de redes sociais (item 3.2).

Assim, interessa-nos observar como os conceitos estão inter-relacionados na rede dos enunciados repetidos e reforçados pelos atores no Twitter. Para Osgood (1959), a análise dessas co-ocorrências em mensagens espontâneas pode auxiliar a compreender as ideologias presentes e as representações sociais dos discursos.

\subsection{Análise de Redes Sociais}

A Análise de Redes Sociais (ARS) é uma abordagem teórico-metodológica focada na análise da estrutura social, baseada no estudo dos atores sociais (nós ou nodos) e suas interconexões (relações entre os nós), a partir da análise de clusterização (Degenne \& Forsé, 1999). A ARS, assim, constitui modos de observar as inter-relações na rede e constitui-se em torno de vários conceitos, como "redes", "relações" e "estruturas" (Wasserman \& Faust, 1994). O foco da ARS é a estrutura dos grupos sociais, mas suas premissas podem ser utilizadas

15 Textometrica - http://textometrica.humlab.umu.se/ 
para a análise estrutural de outros elementos que possuam inter-relações. No nosso caso, utilizamos as técnicas da ARS para compreender as conexões entre as palavras e conceitos utilizados nas falas dos atores. Na ARS, há dois tipos de variáveis: as estruturais e as de composição (Wasserman \& Faust, 1994). As primeiras constituem-se em medidas entre os pares de atores e os componentes da rede. As segundas dizem respeito aos atributos dos atores, que referem-se ao ator na sua particularidade. As variáveis estruturais que utilizaremos neste trabalho, assim, referem-se à frequência de conexão (frequência em que aparecem juntas) das palavras utilizadas nos tweets e suas conexões. As variáveis de composição, por outro lado, referem-se às palavras (conceitos) que aparecerem mais e com mais força nos tweets analisados.

A Análise de Redes Sociais geralmente trabalha com grafos, ou seja, visualizações das conexões do universo estudado. Grafos podem ser direcionados (quando a conexão segue uma direção, por exemplo, A-> B) e não direcionados (quando a conexão não segue uma direção, por exemplo $\mathrm{A}<->\mathrm{B}$ ).

Embora a ARS disponha de várias medidas e abordagens para analisar as estruturas do corpus, neste trabalho privilegiamos algumas das mais simples:

a) Grau de Conexão - O grau de conexão refere-se à "força" da conexão entre dois nós. Quanto maior o grau, mais forte é a conexão entre os nós. O grau de conexão é uma medida numérica, normalmente referida como o somatório de todas as conexões existentes entre A e B. Quando o grafo é direcionado, há um grau in (indegree - quantas conexões o nó recebe) e in out (outdegree - quantas conexões o nó faz).

b) Centralização - A centralização é uma medida de quão centralizado um grafo está em torno de determinados nós. Scott (2004) define a centralização em relação à densidade. Para o autor, enquanto a densidade foca o "nível de coesão geral" de um grafo (aqui entendido como o quão interconectado ele está), a centralização enfatiza o número de pontos focais em torno das quais essa coesão está organizada (p.89). Por isso, diz-se que essas medidas são complementares.

Embora estejamos trabalhando com a materialidade dos discursos, esses discursos representam uma plêiade de atores e de práticas sociais que justificam, assim, a abordagem dos conceitos da ARS.

Para analisar esses dados, utilizou-se o software Gephi ${ }^{16}$.

\section{O \#DIADACONSCIÊNCIANEGRA NO TWITTER}

Nossa análise será dividida em três momentos. No primeiro, explicamos a codificação dos dados e as escolhas de inferências. No segundo, analisamos as co-ocorrências e as relações entre os dados. No terceiro, fazemos a discussão dos dados com relação aos elementos teóricos apresentados no capítulo anterior.

${ }^{16}$ Software de visualização de redes - https://gephi.org/ 


\subsection{Exposição, Codificação e Classificação dos Dados}

Conforme explicamos, o primeiro procedimento foi a coleta de dados. Após a coleta, procedeu-se à análise com a criação dos conceitos como categorias de análise. Assim, observamos quais temos, no conjunto de dados, ocorriam com maior frequência. Esses termos foram codificados em conceitos mais gerais (Tabela 1).

\begin{tabular}{|c|c|c|}
\hline Termos & Frequência & Conceito \\
\hline negra & 89 & \multirow[t]{6}{*}{ negro } \\
\hline negro & 33 & \\
\hline negros & 20 & \\
\hline preta & 15 & \\
\hline nêgra & 10 & \\
\hline afro & 8 & \\
\hline hoje & 30 & \multirow[t]{6}{*}{ data } \\
\hline dia & 47 & \\
\hline novembro & 28 & \\
\hline diadaconsciêncianegra & 20 & \\
\hline dias & 18 & \\
\hline diadaconsciencianegra & 9 & \\
\hline cor & 30 & cor \\
\hline preconceito & 29 & preconceito \\
\hline consciência & 27 & \multirow[t]{2}{*}{ consciênci } \\
\hline consciencia & 8 & \\
\hline zumbi & 26 & \multirow[t]{2}{*}{ zumbi } \\
\hline palmares & 13 & \\
\hline feriado & 25 & feriado \\
\hline brasil & 22 & \multirow[t]{2}{*}{ brasil } \\
\hline nacional & 17 & \\
\hline racismo & 22 & \multirow[t]{3}{*}{ racismo } \\
\hline racista & 16 & \\
\hline racistas & 10 & \\
\hline humana & 22 & humana \\
\hline branco & 16 & \multirow[t]{3}{*}{ branco } \\
\hline branca & 15 & \\
\hline brancos & 8 & \\
\hline todos & 16 & todos \\
\hline
\end{tabular}




\begin{tabular}{|c|c|c|}
\hline feliz & 16 & feliz \\
\hline respeito & 15 & respeito \\
\hline igualdade & 14 & \multirow[t]{2}{*}{ igualdade } \\
\hline iguais & 13 & \\
\hline orgulho & 13 & orgulho \\
\hline reflexão & 13 & reflexão \\
\hline luta & 12 & luta \\
\hline história & 12 & história \\
\hline mundo & 11 & mundo \\
\hline amarela & 11 & amarela \\
\hline homenagem & 10 & homenagem \\
\hline liberdade & 10 & liberdade \\
\hline parda & 10 & parda \\
\hline racial & 10 & \multirow[t]{2}{*}{ raça } \\
\hline raça & 9 & \\
\hline albino & 10 & albino \\
\hline escurinho & 9 & escurinho \\
\hline bom & 13 & \multirow[t]{2}{*}{ feliz } \\
\hline feliz & 16 & \\
\hline
\end{tabular}

Tabela 1: Classificação do Conteúdo dos Tweets

A partir desta codificação, foi calculada a co-ocorrência entre os vários conceitos (a mínima foi 4 e a máxima, 9). As co-ocorrências foram selecionadas a partir de sua força (normalizada) até o limite de 0.8 (92 co-ocorrências de 325). A partir destes dados, gerou-se o grafo, buscando apontar as interconexões entre os conceitos. O grafo, assim, contém 92 conexões e 26 nós. Os 26 nós são representados pelos conceitos: feliz, racismo, zumbi, história, cor, negro, raça, reflexão, homenagem, branco, liberdade, feriado, respeito, parda, luta, albina, data, humana, todos, brasil, igualdade, consciência, preconceito, amarela, escurinho, orgulho. Esses conceitos foram classificados em conceitos ainda mais abrangentes (Tabela 2). Em primeiro lugar, os "atores", ou seja, os conceitos que, de alguma maneira, poderiam fazer referência a algum sujeito (ou grupo) na fala. $\mathrm{O}$ segundo grupo compreende os conceitos associados a valores positivos. $\mathrm{O}$ terceiro grupo, a valores negativos na sociedade. Finalmente, o último grupo compreende os conceitos "contextuais", ou seja, aqueles que focam elementos mais materiais da data. 
Cadernos de ESTUDOS LINGüÍSTICOS (56.2) - Jul./Dez. 2014

\begin{tabular}{|l|l|l|l|}
\hline \multicolumn{1}{|c|}{ Atores } & Valores Positivos & Valores Negativos & \multicolumn{1}{|c|}{ Contexto } \\
\hline Negro & liberdade & Racismo & História \\
Zumbi & respeito & Preconceito & Cor \\
Branco & igualdade & & Raça \\
Albina & consciência & Feriado \\
Parda & orgulho & \\
Todos & feliz & & \\
Amarela & reflexão & & \\
Escurinho & luta & & \\
Humana & homenagem & & \\
Brasil & & & \\
\hline
\end{tabular}

Tabela 2: Criação das Categorias de Conceitos

\subsection{Redes de Co-Ocorrências}

A seguir, observaremos os grafos das associações entre os conceitos. Para esta análise, escolhemos a categoria "atores" como guia, no sentido de mostrar como os demais conceitos se articulam em torno das redes associadas aos atores.

No primeiro grafo (Figura 1), vemos as conexões entre as co-ocorrências dos conceitos. Cada conceito é representado por um nó e cada co-ocorrência pela conexão. Quanto mais "forte" a conexão, mais grossa ela aparece na imagem. Os nós também estão representados pela quantidade de conexões que recebem. Assim, quanto maior o indegree, maior o nó. Vemos que, dentre os atores, os conceitos que aparecem com mais força são "branco" e "brasil". Logo a seguir, vemos "albino" (indegree entre 5 e 11) (Figura 2). Dentre os conceitos de valores positivos, o que mais aparece é "feliz". Dentre os contextos, "feriado" e "cor". Esse primeiro dado é relevante porque já indica quais elementos receberam mais destaque nas diversas falas, associados a um maior número de conceitos. "Feriado" e "feliz" são conceitos bastante significativos neste sentido.

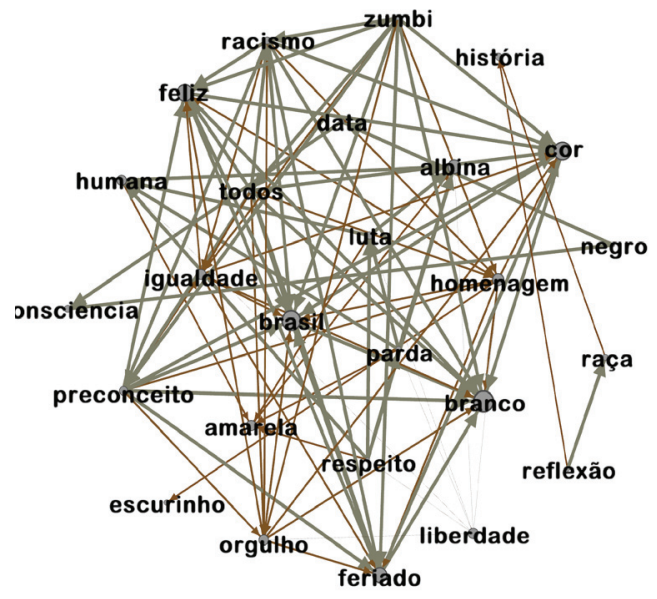

Figura 1: Grafo com os conceitos e suas interconexões

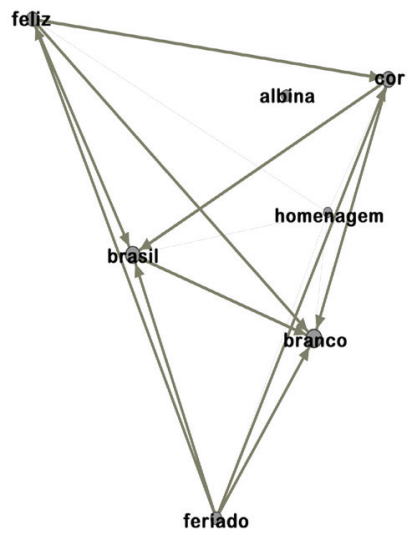

Figura 2: Nós com maior indegree e suas conexões 
Outro detalhe importante é a centralização do grafo. No modelo de Fuchterman-Rheingold, utilizado para plotar os dados, os nós mais conectados tendem a assumir uma posição mais central no grafo. Ou seja, aqueles nós que apresentam maior quantidade de co-ocorrências estão posicionados no centro. Observamos que entre estes nós estão alguns atores: "brasil, "parda", "amarela", "todos", "albina", alguns valores positivos como "luta", "homenagem", "igualdade" e um contextual, "data". Os nós que estão na parte mais externa do grafo aparecem como conceitos menos frequentes e menos conectados nos discursos explicitados nas falas do Twitter. É curioso que o ator "negro" apareça pouco conectado e pouco central nas falas.

A seguir, passamos a analisar melhor as interconexões entre os conceitos centrados nos atores. Na primeira análise, observaremos as interconexões entre os conceitos em torno de "branco" (Figura 3). Observamos que este conceito é um dos que mais recebem conexões e por isso seu indegree é maior. Isso significa que é um conceito que aparece mais conectado aos demais conceitos. Na figura, podemos ver que ele está fortemente conectado aos atores "zumbi" e "todos", e ao valor positivo "feliz", além dos negativos "racismo", "preconceito". Finalmente, "cor" e "feriado", elementos contextuais também aparecem. De forma fraca, o ator está também conectado aos valores positivos "homenagem", "igualdade" e "orgulho". Vemos, portanto, que a este ator estão conectados principalmente valores negativos, de forma forte, com os valores positivos aparecendo de forma fraca.

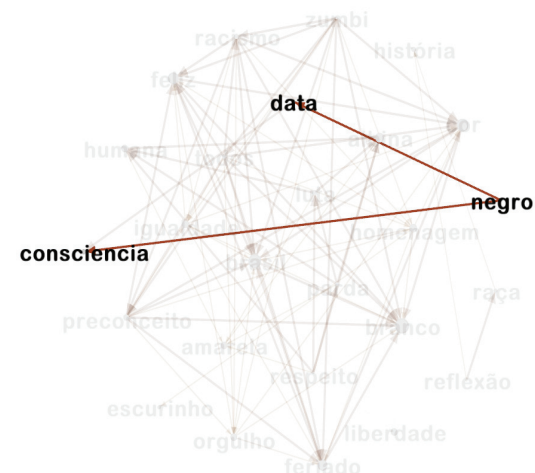

Figura 3: Rede do conceito-ator "negro"

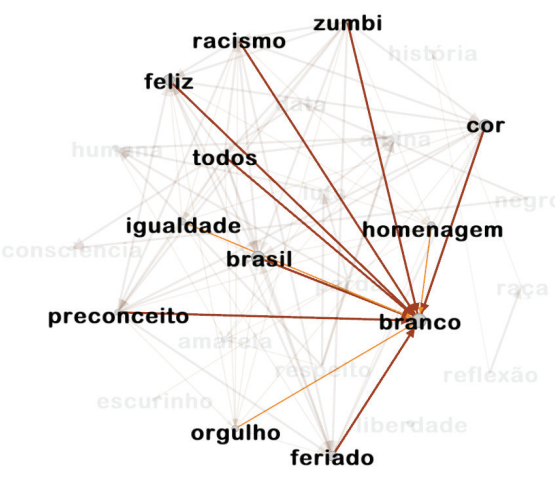

Figura 4: Rede do conceito-ator "branco"

Por outro lado, quando consideramos o conceito-ator "negro", vemos que ele está fortemente conectado a apenas dois outros conceitos, "data" e "consciência". Em ambas as conexões, a força é dada pela associação de "negro" com os dois conceitos, e não o contrário. O primeiro é contextual e o segundo é um valor positivo (entretanto, poderia também ser associado ao contexto, uma vez que se trata do dia da "consciência" negra). Isso parece indicar que o conceito "negro" foi mais utilizado em um contexto de falas focadas na data e não nos demais valores (Figura 4). 


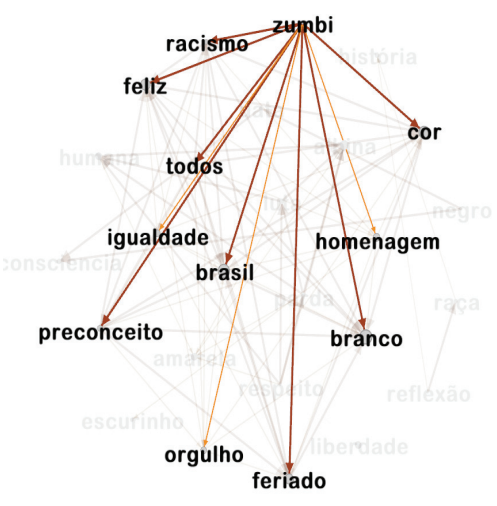

Figura 5: Rede em torno do conceito-ator "zumbi

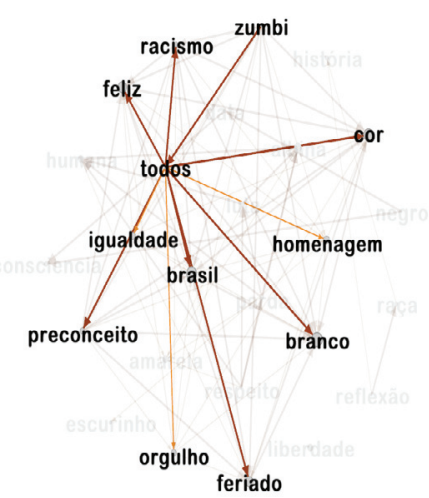

Figura 6: Rede em torno do conceito-ator "todos"

Observemos agora o conceito "zumbi". Curiosamente, o conceito apenas faz conexões, não as recebe. O conceito-ator parece fortemente conectado com outros três atores "branco", "todos" e "brasil". Além disso, aparece fortemente conectado com o valor positivo "feliz" e com os valores negativos "racismo" e "preconceito". Está fracamente conectado aos valores positivos "igualdade", "orgulho" e "homenagem" (Figura 5). Isso parece implicar que a palavra foi associada ao racismo e ao preconceito, bem como à data. Entretanto, não aparece conectada com o conceito "negro".

$\mathrm{Na}$ Figura 6, vemos o conceito-ator central "todos". Este conceito está associado fortemente aos atores "zumbi" (conexão in), "brasil" e "branco" (conexão out). Além disso, está fortemente associado ao valor positivo "feliz" e aos valores negativos "preconceito" e "racismo" e ao contexto "feriado" e "cor". Também está associado fracamente aos valores positivos "homenagem" e "orgulho". Importante observar que, embora "zumbi" apareça com coocorrências com "todos", "todos" não aparece conectado a "zumbi". Também é relevante ressaltar que, novamente, os atores conceito "negro", "pardo", "escurinho" não aparecem.

Na Figura 7 temos o conceito ator "albina". No caso, o conceito recebe conexões, mas não as faz. Conecta-se fortemente a "parda "e "humana" e fracamente a "amarela", como outros atores. Conecta-se também fortemente aos valores positivos "respeito" e "luta", e fracamente a "liberdade". 


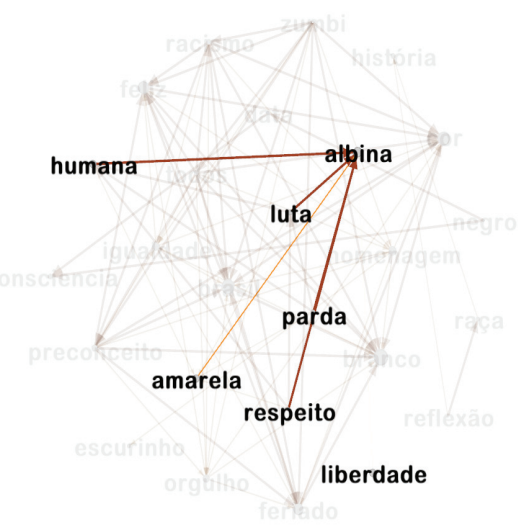

Figura 7: Rede em torno do conceito-ator "albina"

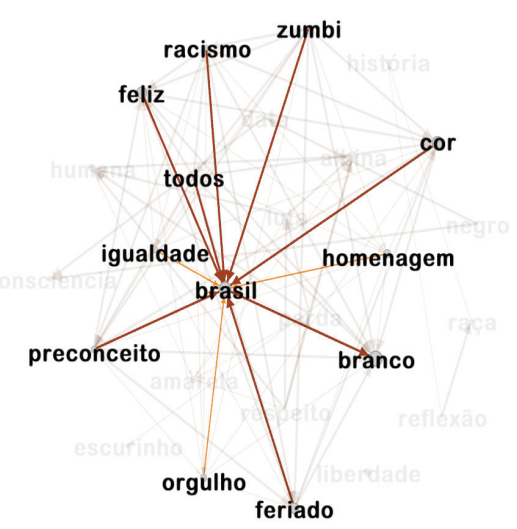

Figura 8: Rede em torno do conceito-ator "Brasil"

Na Figura 8 está o conceito-ator mais central de todos, o "Brasil". Consideramos o conceito como um ator porque entendemos que, qualitativamente, suas referências podem ser facilmente compreendidas como "povo brasileiro". Também recebe conexões dos atores "todos e "zumbi". Faz conexão forte com "branco". Depois conecta-se fortemente aos valores negativos "racismo" e "preconceito" e ao valor positivo "feliz". Conecta-se fracamente a "igualdade", "homenagem" e "orgulho" como valores positivos, e a "cor" e "feriado" como conceitos-contexto. Novamente, nenhum termo relacionado a negritude, além de "zumbi", é associado ao ator "brasil".

Na Figura 9, temos o termo "escurinho". Observamos que o mesmo está diretamente associado, de forma fraca, a apenas um outro conceito, "homenagem". Outro ator-conceito que também aparece fracamente conectado é "amarela", ligado unicamente a "humana", "luta", "albina", "parda" e "respeito". Note-se que há três outros atores (humana, albina e parda) e dois valores positivos (luta e respeito) (Figura 10).

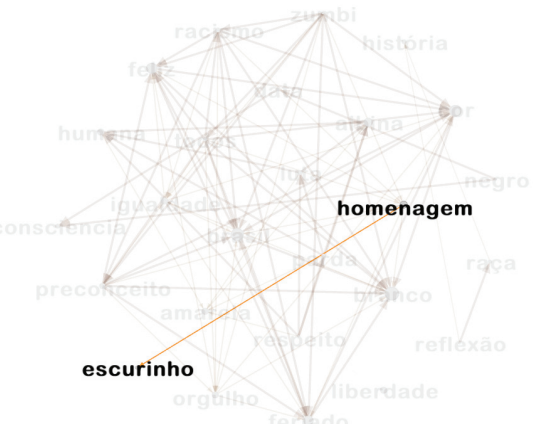

Figura 9: Rede em torno do conceito-ator "escurinho"

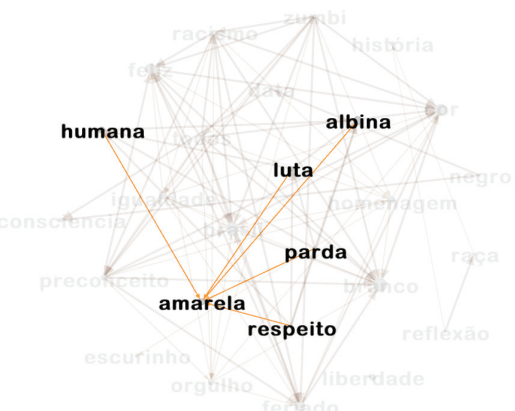

Figura 10: Rede em torno do conceito-ator "amarela" 


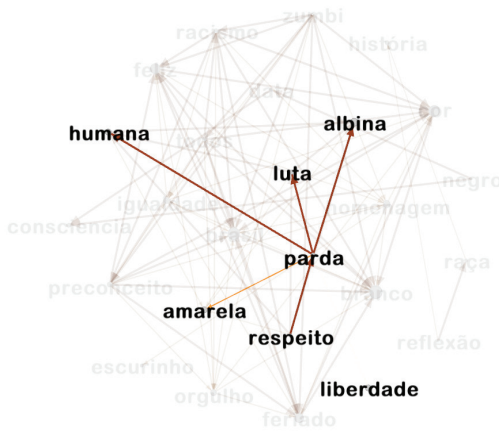

Figura 11: Rede em torno do conceito-ator "parda"

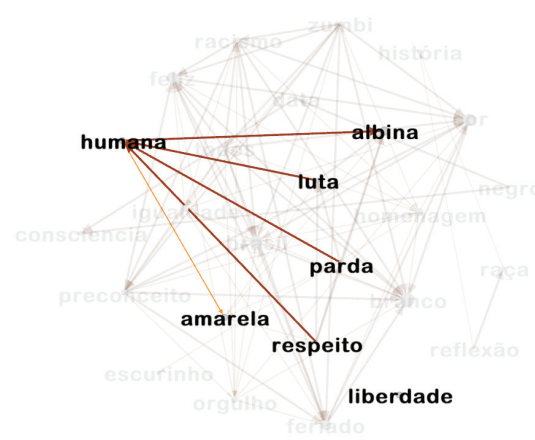

Figura 12: Rede em torno do conceito-ator "humana"

Finalmente, na Figura 11, temos o ator "parda". Vemos que está fortemente conectado a "albina" e a "humana", como outros atores. Ao mesmo tempo, conecta-se fracamente a "amarela". Também está fortemente conectado aos valores positivos "luta" e "respeito" e fracamente, a "liberdade". Na Figura 12, temos as conexões recebidas e feitas pelo conceito "humana". É relevante perceber que "albina", "parda" e "amarela" estão conectados ao conceito, bem como "luta". É relevante perceber entretanto, que "branco" e "negro" não estão presentes.

\subsection{O Discurso, a Exclusão e a Violência Simbólica}

A partir do que foi acima exposto, capítulo anterior, podemos perceber que a rede de co-ocorrências pode indicar quais conceitos aparecem em contextos diferentes na data. Por exemplo, atores mais associados a conceitos negativos ou positivos poderiam indicar uma formação discursiva (Foucault, 1999) mais frequente. Nesta análise mais abrangente, portanto, percebemos alguns elementos relevantes.

Primeiramente, que os conceitos referentes ao ator "negro" quase não estão presentes nas falas do Twitter. Também é importante observar que o conceito "negro", embora apareça mais vezes no corpus, foi quase integralmente associado à data, e não a seus sentidos. Na verdade, suas relações com os demais conceitos foram inexistentes. Isso parece indicar uma homogeneidade em torno do conceito (referência à data). É importante observar isso em oposição ao conceito "branco", que aparece muito mais conectado aos conceitos negativos e positivos da data. Esse conceito não só aparece mais conectado a "racismo", "preconceito", "cor" e "orgulho" do que o "negro", como igualmente é um dos principais nós na rede. Esses dados também apontam para um uso mais amplo do conceito, mais focado em contextos diferentes (tanto na associação com "racismo" e "preconceito", quanto na associação - mais fraca - com "orgulho" e "igualdade"). Esses indícios poderiam significar que o conceito aparece em maior evidência em discursos diferentes, associando valores positivos e negativos a "branco". 
Nota-se, assim, que o conceito "negro" está excluído da rede de conceitos. É reduzido à descrição da data, com um papel pouco central. A discussão que poderíamos esperar da menção à data e ao que ela representa não aparece. O "negro", assim, parece excluído do debate da data, interditado (Foucault, 1999), proibido, apenas representado quando "se pode" falar da relação com a data, sendo uma espécie de ritual de circunstância da interdição.

Outros dois atores que ajudam a compreender melhor esses discursos são "albina" e "amarela". Suas presenças associadas a "luta" e "respeito", além de "humana", trazem indícios fortes de uma dissolução da questão do "negro" no contexto da data. A própria presença das referências "parda" e "escurinho" também parecem indicar que "negro", como ator, aparece em segundo plano na discussão em torno da data. Ao contrário, a discussão está centrada nos atores "branco", "brasil" e "todos". "Negro", entretanto, não está conectado a "todos". A própria presença desses conceitos evidencia também a ausência daquele em que a data está centrada. O uso dos termos "pardo" e "escurinho" (e mesmo de "zumbi”) para referenciar o negro traz ainda mais evidências da interdição do termo "negro". Vemos, assim, que há um reforço dos temas da questão racial centrados em outros atores, que não o negro. Há um desvio do foco no debate instigado pela data para outras "minorias", incluindo aí o próprio "branco", este sim associado aos conceitos positivos, evidenciando os efeitos do discurso de dominação.

Vemos, assim, uma ação de exclusão (Foucault, 1999; Hall, 2001) que, em pequena escala, poderia não ser perceptível, mas em grande escala, parece evidenciar um discurso dominante: aquele no qual "negro" é interditado, onde a discussão sobre a questão da raça é rapidamente agregada aos demais conceitos representativos de raça ("albino" e "amarelo" por exemplo). A rede, que agrega ao discurso da raça, do respeito, da luta pelos direitos do negro como um discurso de "todos" ("Todos", "amarelos", "brancos", "albinos"...). Curiosamente, não o "negro".

A exclusão e a marginalização do conceito, sempre ligado à data, parece, portanto, evidenciar a interdição do discurso do e sobre o "negro". Assim, os sujeitos parecem mencionar a data diante da questão histórica ("zumbi") e pela questão da percepção das qualidades do feriado ("feriado", "feliz", "homenagem"). A centralização do grafo em torno de conceitos externos à discussão e a construção de uma rede "isolada" do centro para "negro" também mostram essa exclusão.

Esse apagamento, essa exclusão, é signo da violência simbólica (Bourdieu, 1991) do discurso no Twitter. Trata-se de uma violência não explícita, mas legitimada, reforçada e reconstruída nas assimetrias das relações de poder no espaço das redes sociais online (conforme afirma Herring, 2001). Essa violência aparece com força quando analisamos as redes em torno dos conceitos dos tweets e sua associação com valores positivos e negativos.

Essas associações, assim, parecem reproduzir o discurso de dominação no Brasil, onde a questão da raça cai na invisibilidade do negro, conforme explicitado por Golzio (2004). A violência simbólica, nessas circunstâncias, teria ainda um impacto mais significativo, a partir do momento em que a replicabilidade, a buscabilidade e o arquivamento das mensagens multiplicam e naturalizam a visibilidade (ou ainda a exclusão) presentes no discurso. A data, assim, fica 
reduzida à questão do feriado, tornando irrelevante sua associação com o debate racial, com a questão histórica e com o desvelamento da dominação.

\section{CONCLUSÕES}

Neste artigo, procuramos explorar a Análise de Conteúdo conjuntamente com a Análise de Redes para o estudo dos discursos presentes no Twitter, através de um estudo quali-quantitativo de larga escala. A proposta foi construir um estudo focado na AC de tipo Relacional e a Análise Estrutural a partir da abordagem da Análise de Redes Sociais. Com esse conjunto de elementos, pudemos analisar as relações entre os conceitos que mais apareceram nos tweets relacionados ao Dia da Consciência Negra. Essa análise de mensagens que foram espontaneamente publicadas na ferramenta na data, delimitadas pelo uso dos termos em conjunto, mostra, assim, os conceitos que mais apareceram nesses tweets e suas inter-relações.

Pudemos perceber, deste modo, a exclusão do termo "negro" das relações principais com os valores positivos e negativos da data, e do âmbito da discussão em geral, reduzindo-o unicamente à referência da data. Apesar de mais citado, é assim o conceito, que está menos envolvido com os demais, menos presente na rede, mais marginalizado e menos central. Nos discursos no Twitter, outros conceitos, referentes a outros atores (como "branco"), tomam a frente, tornando-se mais centrais na rede e mais ricos em conexões com outros conceitos. Há, portanto, evidências de uma reprodução da violência simbólica do discurso de raça, sendo o negro não partícipe do "todo" social, mas marginalizado.

Embora essas conclusões façam parte ainda de experimentos realizados por meio do design metodológico e sejam, portanto, limitadas, é relevante perceber, a presença da ideologia (Osgood, 1959), mesmo em ambientes ditos mais plurais. As associações proporcionam indícios relevantes das formações discursivas (Foucault, 2009) presentes no Twitter e, principalmente, entre os usuários mais jovens, aqueles que hoje constituem uma boa parte dos usuários da internet brasileira, conforme discutimos.

\section{$\overline{\text { REFERÊNCIAS }}$}

BARDIN, Laurence. Análise de Conteúdo. Lisboa: Edições 70, 2007.

BARON, N. Foreword. In: Thurlow, C. e Mroczek, C. Digital Discourse: Language in the New Media. Oxford : Oxford University Press, 2011.

BENTO, M. A. S. e BEGHIN, N. Juventude Negra e Exclusão Radical. IPEA. políticas sociais acompanhamento e análise $|11|$ ago. 2005. Disponível em: $<$ http://www.en.ipea.gov.br/agencia/ images/stories/PDFs/politicas_sociais/ENSAIO4_Maria11.pdf> . Acesso em 06 de Janeiro de 2014.

BERNSTEIN, M. BAKSHY, E; BURKE, M.; KARRER, B. Quantifying the Invisible Audience in Social Networks. Proceedings of CHI 2013, April 27-May 2, 2013, Paris, France. 
BOYD, d. Social Network Sites as Networked Publics: Affordances, Dynamics, and Implications. In: Networked Self: Identity, Community, and Culture on Social Network Sites (ed. Zizi Papacharissi), pp. 39-58, 2010.

BOYD, D. M., e ELLISON, N. B. Social Network Sites: Definition, History, and Scholarship. Journal of Computer-Mediated Communication, 13(1), 210-230, 2007.

BOYD, d. GOLDER, S. , LOTAN, G. "Tweet, Tweet, Retweet: Conversational Aspects of Retweeting on Twitter.” HICSS-43. IEEE: Kauai, HI, January 6, 2010. Disponíve em: <http://www.danah. org/papers/TweetTweetRetweet.pdf> Acesso em 06/01/2014.

CASTELLS, M. A Galáxia da Internet. Rio de Janeiro: Jorge Zahar, 2003.

DEGENNE, A. e FORSÉ, M. Introducing Social Networks. London: Sage, 1999.

FREITAS, M. Refletir sobre a história do Negro no Brasil: Uma resposta ao racismo. II Congresso de Educação - UEG/UnU Iporá - A formação de professores: uma proposta de pesquisa a partir da reflexão sobre a prática docente, 2012. Disponível em: <http://www.cdn.ueg.br/arquivos/ipora/ conteudoN/975/CE_2012_27.pdf $>$. Acesso em 05/01/2014.

FOUCAUlT, M. A Ordem do Discurso. Aula Inaugural no Collège de France. 02 de dezembro de 1970. São Paulo: Ediçoes Loyola, 5a edição, 1999.

FOUCAULT, M. A Arqueologia do Saber. Rio de Janeiro: Forense Universitária, 2009.

GIACOMONI, M. P, e VARGAS, A. Z. Foucault, a Arqueologia do Saber e a Formação Discursiva. Veredas, 2/2010, p. 119-129. Disponivel em: <http://www.ufjf.br/revistaveredas/files/2010/04/ artigo-09.pdf>. Acesso em 28/12/2013.

GOLZIO, D. Exclusão informativa: representação e representatividade dos negros e afrodescendentes nas capas da revista Veja. III SOPCOM, VI LUSOCOM e II IBÉRICO - Volume III. Em: Biblioteca Online de Ciências da Comunicação, 2004. Disponível em: <http://www.bocc.ubi. pt/pag/golzio-derval-exclusao-informativa-representacao-e-representatividade-dos-negros-eafrodescendentes-nas-capas-da-revista-veja.pdf $>$ Acesso em 06/01/2014.

HALL, S. Foucault: Power, Knowledge and Discourse. In: Discourse Theory and Practice: A Reader Edited by Margaret Wetherell, Stephanie Taylor, Simeon J Yates. London: Sage, 2001. (pp. 324 - 344)

HERRING, S. Computer-Mediated Discourse. In: Handbook of Discourse Analysis, edited by Deborah Tannen, Deborah Schiffrin, and Heidi, Hamilton. Oxford: Blackwell. 2001. Disponível em: $<$ http://www.let.rug.nl/redeker/herring.pdf $>$. Acesso em 02/01/2014.

HONEYCUTT C., \& HERRING, S. C. Beyond microblogging: Conversation and collaboration via Twitter. Proceedings of the Forty-Second Hawai'i International Conference on System Sciences (HICSS-42). Los Alamitos, CA: IEEE Press, 2009. Disponível em: <http://ella.slis.indiana. edu/ herring/honeycutt.herring.2009.pdf>. Acesso em 02/01/2014.

KRIPPENDORF, K. Content Analysis, An Introduction to Its Methodology. 3a Ed. Thousand Oaks, CA: Sage Publications, 2012.

OSGOOD, C. The representational model and relevant research methods. In: POOL, I. de S. Trends in Content Analysis, Urban, Univ. of Illinois Press, 1959. 
PAGE, R. The linguistics of self-branding and micro-celebrity in Twitter: The role of hashtags. Discourde \& Communication: May 2012 vol. 6 no. 2, pp. 181-201.

RAMBE, P. Critical discourse analysis of collaborative engagement in Facebook postings. Australasian Journal of Educational Technology, 2012, 28(2), 295-314.

RECUERO, R. Redes Sociais na Internet. Porto Alegre: Sulina, 2009.

RECUERO, Raquel; ZAGO, Gabriela. RT, por favor: considerações sobre a difusão de informações no Twitter. Revista Fronteiras (Unisinos), 2010. Disponível em: <http://www.fronteiras.unisinos. br/index.php? $=5 \& s=9 \& a=88>$. Acesso em 05/01/2014.

ROSEN, D., STEFANONE, M.; LACKAFF, D. Online and Offline Social Networks: Investigating Culturally-Specific Behavior and Satisfaction. Proceedings of the 43rd Hawaii International Conference on System Sciences, 2010.

SCOTT, J. Social Network Analysis. A handbook. 2a ed. London: Sage, 2004.

SOUZA, C.; AMARAL, M.; GUIMARAES, S. A multifuncionalidade do Twitter sob a perspectiva da Análise Crítica do Discurso: uma análise de tweets sobre a profissão-perigo professor. Linguagens e Diálogos, v. 2, n. 1, p. 1-30, 2011.

STEINFELD, C., ELLISON, N. \& LAMPE, C. Social capital, self-esteem, and use of online social network sites: A longitudinal analysis. Journal of Applied Developmental Psychology, 29 (6), 2008, 434-445. Disponível em: https://www.msu.edu/ steinfie/Steinfield_Ellison_Lampe(2008). pdf. Acesso em agosto de 2013.

WASSERMAN, S. \& FAUST, K. Social Network Analysis. Methods and Applications. Cambridge, Cambridge University Press: 1994.

WALTON, S. e JAFFE, A. Stuff White People Like': Stance, Class, Race and Internet Commentary. In: Language in the New Media: Sociolinguistic Perspectives, edited by Crispin Thurlow and Kristine Mroczek. Oxfored University Press, 2011.

ZAPPAVIGNA, M. Ambient affiliation: A linguistic perspective on Twitter. New Media \& Society August 2011 13: 788-806, Maio de 2011 doi:10.1177/1461444810385097

ZAGO, Gabriela. Dos Blogs aos Microblogs: Aspectos Históricos, Formatos e Características. VI Congresso Nacional de História da Mídia - maio de 2008 em Niterói, RJ. Disponível em <http:// bocc.ubi.pt/pag/zago-gabriela-dos-blogs-aos-microblogs.pdf $>$. Acesso em 02/01/2014. 